\title{
Analisis Kedip Tegangan Akibat Gangguan Hubung Singkat pada Sistem Jaringan Distribusi 20 kV di Penyulang Kenari Gardu Induk Seduduk Putih
}

\author{
${ }^{1}$ Asri Indah Lestari, ${ }^{2}$ Taufik Barlian, ${ }^{3}$ Wiwin A Oktaviani \\ Jurusan Teknik Elektro Universitas Muhammadiyah Palembang, Palembang \\ Jl. Jenderal Ahmad Yani 13 Ulu Seberang Ulu II, 13 Ulu, \\ Kec. Plaju, Kota Palembang, Sumatera Selatan 30116 \\ ${ }^{1}$ asriindahhh@gmail.com \\ 2tfk_ap@yahoo.com \\ ${ }^{3}$ winarvin@yahoo. com
}

Intisari - Kestabilan ditunjukkan oleh lama terjadinya kedip tegangan, lamanya kedip tegangan menunjukkan tingkat kestabilan tegangan pada sistem tenaga listrik. Salah satu parameter yang menunjukkan kualitas sistem tenaga listrik adalah tegangan. Tujuan dari penelitian ini adalah untuk mengidentifikasi besaran dan lokasi dimana arus gangguan hubung singkat terbesar dan menghitung besaran kedip tegangan di Penyulang Kenari. Kedip tegangan dihitung berdasarkan panjang penyulang yang mengalami gangguan, titik gangguan, impedansi sumber, reaktansi urutan transformator, impedansi urutan penyulang dan ekivalen jaringan, arus gangguan hubung singkat 1 fasa ke tanah, 2 fasa, 3 fasa, tegangan urutan setiap jenis gangguan. Hasil dari perhitungan menunjukkan arus gangguan hubung singkat terbesar untuk setiap jenis gangguan pada panjang total saluran $8,7 \mathrm{~km}$ dan $2,89 \mathrm{~km}$ berada di titik gangguan $20 \%$ dari panjang total saluran, sedangkan kedip tegangan terbesar pada panjang total saluran $8,7 \mathrm{~km}$ untuk 1 fasa ke tanah dan 3 fasa berada di titik gangguan $100 \%, 2$ fasa berada di titik gangguan $80 \%$, dan pada panjang total saluran 2,89 untuk 1 fasa ke tanah berada di titik gangguan $80 \%, 2$ fasa dan 3 fasa di titik gangguan $100 \%$.

Kata kunci - Kedip Tegangan, Gangguan Hubung Singkat, Penyulang Kenari.

Abstract - Stability is shown by the length of the voltage sag, the length of the voltage sag indicates the level of voltage stability in the electric power system. The parameter that shows the quality of the electric power system is voltage. The purpose of this research are to identify the magnitude and location of the largest short circuit fault current and to calculate the magnitude of voltage sag in Kenari's feeder. The voltage sag is calculated based on the length of the feeder which has a problem, the fault node, the source impedance, resistance sequence transformer, impedance of feeder sequence and network equivalent, one-phase of short circuit fault current of ground, two-phase, three-phase, voltage sequence of each type of fault. The results of the calculation show the largest short circuit fault current for each type of fault in a total feeder length of 8,7 $\mathrm{km}$ and $2,89 \mathrm{~km}$ at the point of fault $20 \%$ of the total feeder length, so that the largest voltage sag at $8,7 \mathrm{~km}$ of total feeder length for one-phase to ground and three-phase are at the point of fault $100 \%$, two-phase is at the point of fault $80 \%$ and a total feeder length 2,89 for one-phase to ground is at the point of fault $80 \%$, two-phase and three-phase at point of fault $100 \%$.

Keywords — Voltage Sag, Short Circuit Fault, Kenari’s Feeder.

\section{PENDAHULUAN}

Sistem distribusi adalah sistem tenaga listrik yang menerima tenaga listrik dari gardu induk dan menyalurkan tenaga listrik ke pusat-pusat beban [1]. Suplai daya dari sumber ke beban harus dikirim dengan suatu kontinuitas yang tinggi dengan kualitas yang baik. Hal ini dilakukan untuk menjaga nilai dari mutu listrik yang akan dihasilkan agar tetap memiliki kualitas tegangan yang baik [2]. Salah satu parameter yang menunjukkan kualitas sistem tenaga listrik adalah kedip tegangan (voltage sag). Kedip tegangan dapat disebabkan oleh dua hal, yaitu adanya gangguan hubung singkat, dan adanya penambahan beban yang besar. Penyulang 
Kenari pada sistem distribusi $20 \mathrm{kV}$ Gardu Induk Seduduk Putih Palembang merupakan salah satu penyulang yang menyuplai beban komersil, berupa pusat-pusat perbelanjaan dan bengkel-bengkel yang menggunakan motor listrik berkapasitas besar selain dari beban-beban residensial. Sehingga timbulnya voltage sag pada Penyulang Kenari, utamanya karena terjadinya gangguan hubung singkat, harus segera di atasi agar tidak merusak peralatan penunjang pengoperasian pusat-pusat bisnis tersebut.

\section{TINJAUAN PUSTAKA}

\section{A. Sistem Tenaga Listrik}

Suatu sistem tenaga listrik pada umumnya terdiri dari empat unsur, yaitu pembangkit, transmisi, distribusi dan pemakaian tenaga listrik [3]. Pembangkit tenaga listrik terdiri atas berbagai jenis, seperti Pembangkit Listrik Tenaga Air (PLTA), Pembangkit Listrik Tenaga Uap (PLTU), Pembangkit Listrik Tenaga Diesel (PLTD), Pembangkit Listrik Tenaga Gas (PLTG), Pembangkit Listrik Tenaga Gas dan Uap (PLTGU), Pembangkit Listrik Tenaga Panas Bumi (PLTP), Pembangkit Listrik Tenaga Surya (PLTS).

Tenaga listrik pertama kali dibangkitkan di pembangkit yang pada umunya bertegangan $6 \mathrm{kV}$ sampai $24 \mathrm{kV}$. Tenaga listrik yang dibangkitkan kemudian disalurkan melalui saluran transmisi yang terlebih dahulu dinaikkan tegangannya oleh transformator penaik tegangan [4]. Saluran transmisi mempunyai tegangan tinggi dan tegangan ekstra tinggi. Tegangan tinggi pada umumnya bertegangan $70 \mathrm{kV}, 150 \mathrm{kV}$ dan tegangan ekstra tinggi pada umumnya bertegangan $550 \mathrm{kV}$. Setelah tenaga listrik disalurkan melalui saluran transmisi maka tenaga listrik sampailah di gardu induk untuk diturunkan tegangannya oleh transformator penurun tegangan. Setelah tenaga listrik diturunkan tegangannya menjadi tegangan menengah atau yang disebut saluran distribusi sebesar $20 \mathrm{kV}$. Tenaga listrik diturunkan kembali tegangannya menjadi $220 \mathrm{~V}$ untuk disalurkan ke pemakai tenaga listrik atau konsumen.
B. Gangguan Hubung Singkat Pada Sistem Distribusi

Gangguan hubung singkat adalah gangguan yang terjadi karena adanya kesalahan antara bagian-bagian yang bertegangan. Gangguan hubung singkat dapat terjadi akibat adanya isolasi yang tembus atau rusak karena tidak tahan terhadap tegangan lebih, baik yang berasal dari dalam maupun yang berasal dari luar sistem [5]. Gangguan hubung singkat dalah suatu kondisi pada sistem tenaga dimana penghantar yang berarus terhubung dengan penghantar lain atau dengan tanah. Gangguan yang mengakibatkan hubung singkat dapat menimbulkan arus yang jauh lebih besar dari pada arus normal.

Adapun perhitungan dalam menganalisis gangguan hubung singkat yaitu sebagai berikut :

Arus Gangguan Hubung Singkat 1 Fasa Ke Tanah

$I_{f L-G}=\frac{3 x V_{1}}{z_{0, e k i}+Z_{1 e k i}+Z_{n e k i}}$

Arus Gangguan Hubung Singkat 2 Fasa

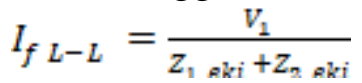

Arus Gangguan Hubung Singkat 3 Fasa

$I_{f} 3 \emptyset=\frac{\frac{V_{1}}{\sqrt{3}}}{Z_{1 e k i}}$

\section{Kedip Tegangan (Voltage Sag)}

Salah satu akibat dari gangguan kualitas daya yang paling umum adalah kedip tegangan [6]. Kedip tegangan adalah peristiwa yang dapat berlangsung dari setengah siklus hingga beberapa detik. Kedip tegangan biasanya terjadi karena memulai pada beban besar, seperti motor listrik. Selain karena motor listrik dengan beban yang besar, kedip tegangan juga terjadi karena gangguan hubung singkat pada sistem kelistrikan baik itu gangguan hubung singkat pada 1 fasa ke tanah, 2 fasa, maupun 3 fasa. Jangka waktu kedip tegangan dibagi menjadi tiga kategori yaitu, seketika, sejenak, dan sementara.

Untuk menghitung kedip tegangan terlebih dulu dihitung tegangan urutan positif, negatif, dan nol. Nilai tegangan 
urutan yang didapatkan dalam bentuk bilangan kompleks dan polar.

Adapun perhitungan yang digunakan dalam kedip tegangan yaitu :

1) Saat gangguan hubung singkat 1 fasa ke tanah

Tegangan urutan positif

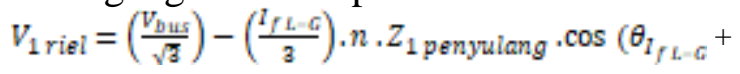

$$
\begin{aligned}
& \left.\theta_{Z \text { Penulang }}\right)
\end{aligned}
$$

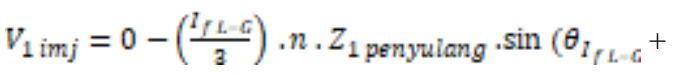

$$
\begin{aligned}
& \left.\theta_{Z \text { Penpulang }}\right)
\end{aligned}
$$

Tegangan urutan negatif

$$
\begin{aligned}
& V_{2 \text { riel }}=-\left(\frac{I_{f d=Q}}{a}\right) \cdot n \cdot Z_{2 \text { penyulang }}{ } \cos \left(\theta_{I_{r d=G}}+\right. \\
& \left.\theta_{Z \text { Penuiang }}\right) \\
& V_{2 \text { imj }}=-\left(\frac{T_{f d-G}}{a}\right) \cdot n \cdot Z_{2 \text { penyulang }} \times \sin \left(\theta_{I_{f i-E}}+\right. \\
& \left.\theta_{Z \text { Penyulang }}\right)
\end{aligned}
$$

Tegangan urutan nol

$$
\begin{aligned}
& V_{\text {o riel }}=0-\left(\frac{I_{f \mathrm{LL}}}{\mathrm{a}}\right) \cdot n \times Z_{0 \text { penyulang }} \cdot \cos \left(\theta_{I_{f \mathrm{~L}=\mathrm{G}}}+\right. \\
& \theta_{Z \text { Penpulang }}
\end{aligned}
$$

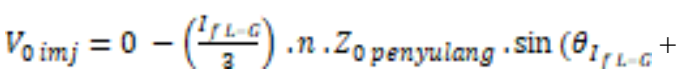

$$
\begin{aligned}
& \left.\theta_{Z \text { Penpulang }}\right)
\end{aligned}
$$

Kedip tegangan saat gangguan hubung singkat 1 fasa ke tanah yaitu dalam bentuk bilangan polar sebagai berikut :

$$
V_{\text {dip 1 }}=\sqrt{\left(\Delta V_{\text {riel }}\right)^{2}+\left(\Delta V_{i m j}\right)^{2}}<\tan ^{-1}\left(\frac{\Delta V_{\text {imf }}}{\Delta V_{\text {riel }}}\right)
$$

2) Saat gangguan hubung singkat 2 fasa

Tegangan urutan positif

$$
\begin{aligned}
& V_{1 \text { riel }}=V_{b u s}-I_{f L-L} \cdot n \cdot Z_{1 \text { penyulang }} \cdot \cos \left(\theta_{I_{f L-1}}+\right. \\
& \left.\theta_{Z \text { Penyulang }}\right) \\
& V_{1 \mathrm{imj}}=0-I_{f L-L}{ } n \times Z_{1 \text { peryyulang }} \sin \left(\theta_{I_{f L \perp}}+\right. \\
& \left.\theta_{Z \text { Penulang }}\right) \\
& V_{1}=\sqrt{\left(V_{1 \text { riel }}\right)^{2}+\left(V_{1 \mathrm{imj} j}\right)^{2}}<\tan ^{-1}\left(\frac{V_{1 \mathrm{fm}}}{V_{1 \text { ried }}}\right)
\end{aligned}
$$

Tegangan urutan negatif

$$
\begin{aligned}
V_{2 \text { riel }}= & V_{b u s}-I_{f L-L} \cdot n \cdot Z_{2 \text { penywlang }} \cdot \cos \left(\theta_{I_{f L-1}}+\right. \\
& \left.\theta_{Z \text { Penywlang }}\right)
\end{aligned}
$$

$$
\begin{aligned}
& V_{2 \text { imj }}=V_{b u s}-I_{f L-L} \cdot n \cdot Z_{2 \text { penyulang }} \cdot \sin \left(\theta_{I_{f L-L}}+\right. \\
& \theta_{z \text { Penyulang }}
\end{aligned}
$$

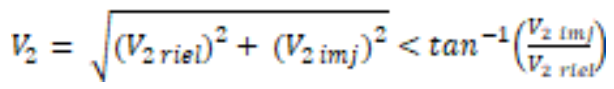

Tegangan pada fasa $\mathrm{R}$

$V_{R_{\text {riel }}}=V_{1 \text { riel }}+V_{2 \text { riel }}$

$V_{R i m i}=V_{1 i m j}+V_{2 i m i}$

$V_{R}=\sqrt{\left(V_{R \text { riel }}\right)^{2}+\left(V_{R} \text { imj } j\right)^{2}}<\tan ^{-1}\left(\frac{V_{R \text { turf }}}{V_{\text {R Fied }}}\right)$

Tegangan pada fasa $S$

$V_{\text {Sriel }}=V_{1} \cos (240+\theta)+V_{2} \cos (120+\theta)$

$V_{S \sin j}=V_{1} \sin (240+\theta)+V_{2} \sin (120+\theta)$

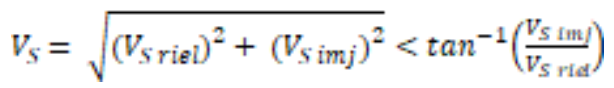

Tegangan pada fasa $\mathrm{T}$

$V_{T \text { riel }}=V_{1} \cos (120+\theta)+V_{2} \cos (240+\theta)$

$V_{T i m j}=V_{1} \sin (120+\theta)+V_{2} \sin (240+\theta)$

$V_{T}=\sqrt{\left(V_{T \text { riel }}\right)^{2}+\left(V_{T \text { imj }}\right)^{2}}<\tan ^{-1}\left(\frac{V_{T} \text { im }}{V_{T \text { File }}}\right)$

Dimisalkan yang mengalami hubung singkat adalah fasa $\mathrm{S}$ dan fasa $\mathrm{T}$ maka besarnya kedip tegangan dalam bentuk bilangan polar adalah :

$$
\begin{aligned}
& V_{\text {dip 2 } \phi}=\sqrt{\left(V_{\text {Sriel }}\right)^{2}+\left(V_{\text {r riel }}\right)^{2}+\left(V_{\text {Simj }}\right)^{2}+\left(V_{T i m j}\right)^{2}}<
\end{aligned}
$$

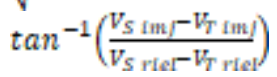

3) Saat gangguan hubung singkat 3 fasa

$$
V_{\text {dip ap }}=\sqrt{\left(Z_{1 \text { penyulang }}\right)^{2}} \times I_{a p} \cdot \sqrt{3}
$$

\section{METODE PENELITIAN}

Langkah kerja pada penelitian ini sebagai berikut :

1. Menghitung impedansi sumber, dimana sumber disini yaitu transformator tenaga. Data yang dibutuhkan untuk menghitung impedansi sumber adalah data $\mathrm{kV}$ pada sisi sekunder dan MVA hubung singkat.

2. Menghitung reaktansi urutan transformator. Data yang dibutuhkan 
untuk menghitung reaktansi urutan positif, negatif, dan nol transformator adalah data reaktansi transformator, dan $\% \mathrm{Z}$ transformator.

3. Menghitung impedansi urutan penyulang di titik gangguan $20 \%, 40 \%, 60 \%, 80$ $\%$, dan $100 \%$ dari panjang penyulang. Data yang dibutuhkan untuk menghitung impedansi urutan penyulang adalah panjang saluran yang terganggu, impedansi urutan penghantar.

4. Menghitung impedansi urutan ekivalen jaringan. Data yang dibutuhkan untuk menghitung impedansi urutan ekivalen jaringan adalah impedansi sumber, reaktansi urutan transformator, tahanan tanah transformator, impedansi urutan penyulang.

5. Menghitung arus gangguan hubung singkat 1 fasa ke tanah, 2 fasa, dan 3 fasa. Data yang dibutuhkan untuk menghitung arus gangguan hubung singkat 1 fasa ke tanah, 2 fasa, dan 3 fasa adalah tegangan sebelum terjadi gangguan, dan impedansi urutan ekivalen jaringan.

6. Menghitung tegangan urutan setiap jenis gangguan. Data yang dibutuhkan untuk menghitung tegangan urutan setiap jenis gangguan adalah tegangan sebelum terjadi gangguan, impedansi urutan penyulang, sudut dari impedansi urutan penyulang, arus gangguan hubung singkat 1 fasa ke tanah, 2 fasa, dan 3 fasa, titik gangguan, dan sudut dari impedansi urutan penyulang.

7. Menghitung kedip tegangan. Data yang dibutuhkan untuk menghitung kedip tegangan adalah tegangan dalam bilangan riel dan tegangan dalam bilangan imajiner.

\section{HASIL DAN PEMBAHASAN}

Penyulang Kenari mengalami 2 keadaan, yaitu :

1. Penyulang dalam keadaan menanggung beban penyulang lain sehingga panjang penyulang menjadi $8,7 \mathrm{~km}$

2. Saat penyulang hanya menanggung beban sendiri dengan panjang total saluran $2,89 \mathrm{~km}$
Tabel 1. Data Transformator Gardu Induk Seduduk Putih

\begin{tabular}{ccc}
\hline Spesiikasi & Transformator & Transformator \\
& $\mathbf{1}$ & 2 \\
\hline Merk & POUWELS & UNINDO \\
Daya & $30 \mathrm{MVA}$ & $30 \mathrm{MVA}$ \\
Tegangan & $70 / 20 \mathrm{kV}$ & $70 / 20 \mathrm{kV}$ \\
Impedansi & $12,24 \%$ & $11,42 \%$ \\
Tahanan & $40 \mathrm{Ohm}$ & $40 \mathrm{Ohm}$ \\
Hubung & Ynyn0 & Ynyn0 (d5) \\
Belitan & $50 \mathrm{~Hz}$ & $50 \mathrm{~Hz}$ \\
Frekuensi & & Penyulang \\
& Penyulang & Murai, \\
& Camar, & Penyulang \\
& Penyulang Pipit, & Merpati, \\
Penyulang & Penyulang \\
Menyuplai & Merak, & Walet, \\
pada & Penyulang & Penyulang \\
Penyulang & Kenari, & Kutilang, \\
& Penyulang Beo, & Penyulang \\
& dan Penyulang & Parkit, dan \\
& Kacer & Penyulang \\
& & Cendrawasi \\
\hline
\end{tabular}

(Sumber : PT. PLN (Persero) Rayon Kenten)

Tabel 2. Reaktansi Penghantar Tegangan 20 kV

\begin{tabular}{cccc}
\hline $\begin{array}{c}\text { Jenis } \\
\text { Penghantar }\end{array}$ & $\begin{array}{c}\text { Impedansi } \\
\text { Urutan } \\
\text { Positif dan } \\
\text { Negatif } \\
(\mathrm{ohm} / \mathrm{km})\end{array}$ & $\begin{array}{c}\text { Impedansi } \\
\text { Urutan } \\
\text { Nol } \\
(\mathrm{ohm} / \mathrm{km})\end{array}$ & $\begin{array}{c}\text { Penghang } \\
\text { (km) }\end{array}$ \\
\hline $\begin{array}{c}\text { N2XSEFGBY } \\
240 \mathrm{~mm}\end{array}$ & $\begin{array}{c}0,0754+ \\
\mathrm{j} 0,10568309\end{array}$ & $\begin{array}{c}0,0754+ \\
\mathrm{j} 0,1057\end{array}$ & 0,27 \\
$\begin{array}{c}\text { AAAC 150 } \\
\text { mm }\end{array}$ & $\begin{array}{c}0,2162+ \\
\text { j0,3305 }\end{array}$ & $\begin{array}{c}0,3631+ \\
\text { j1,618 }\end{array}$ & 8,43 \\
& Total & & 8,7 \\
\hline
\end{tabular}

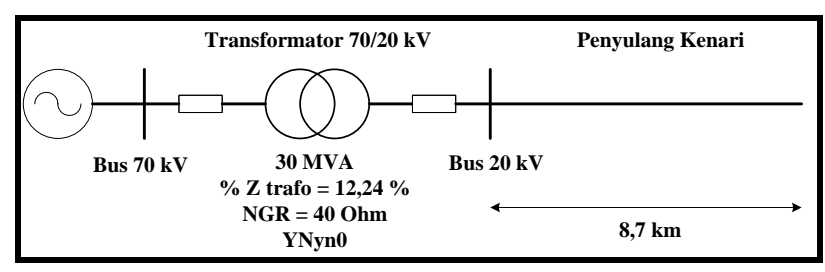

Gbr 1. Penyulang Kenari 
Perhitungan arus gangguan hubung singkat di Penyulang Kenari dengan panjang total saluran $8,7 \mathrm{~km}$ dan $2,89 \mathrm{~km}$ di rangkum dalam grafik berikut :

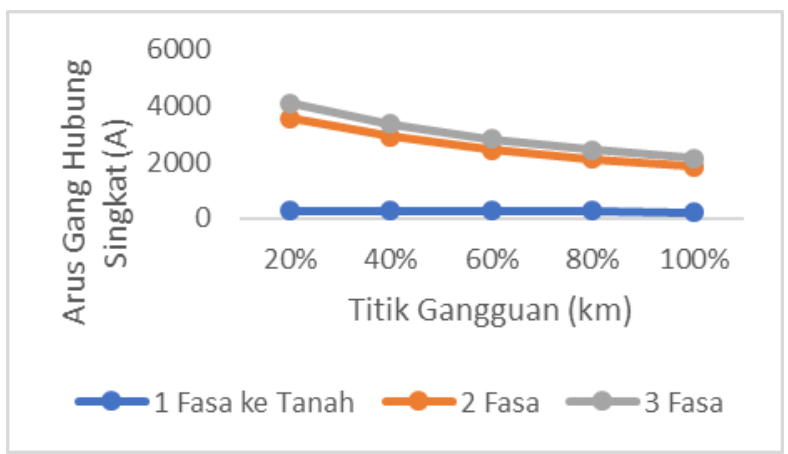

Gbr 2. Grafik arus gangguan hubung singkat dengan panjang total saluran $8,7 \mathrm{~km}$

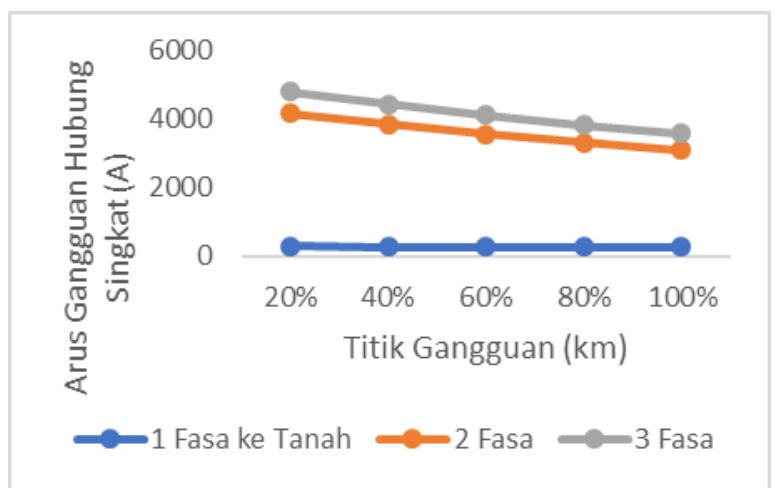

Gbr 3. Grafik arus gangguan hubung singkat dengan panjang total saluran $2,89 \mathrm{~km}$

Perhitungan kedip tegangan di Penyulang Kenari dengan panjang total saluran $8,7 \mathrm{~km}$ dan $2,89 \mathrm{~km}$ di rangkum dalam grafik berikut :

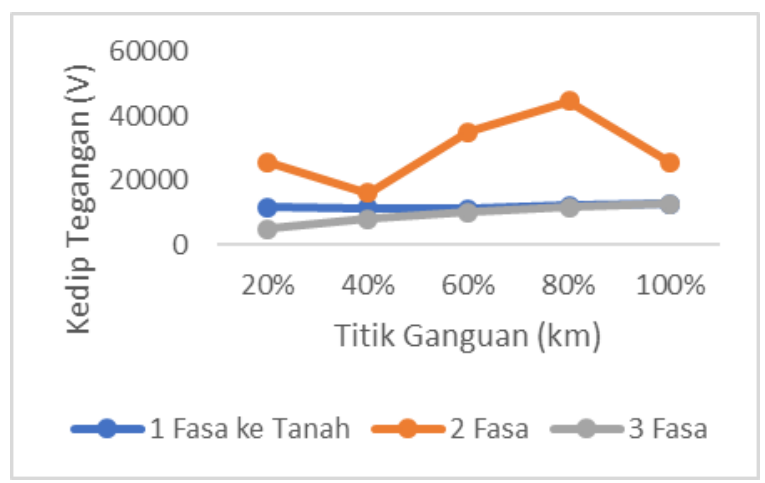

Gbr 4. Grafik kedip tegangan dengan panjang total saluran $8,7 \mathrm{~km}$

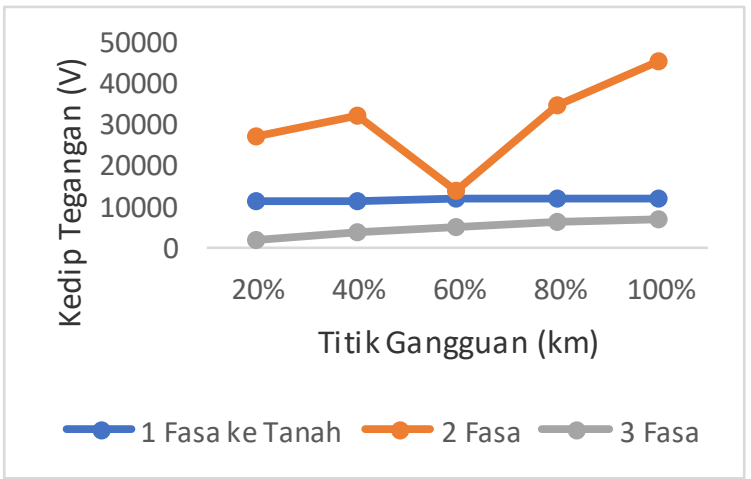

Gbr 5. Grafik kedip tegangan dengan panjang total saluran $2,89 \mathrm{~km}$

\section{PENUTUP}

Kesimpulan dari hasil penelitian ini yaitu :

1. Nilai arus gangguan hubung singkat terbesar dengan panjang total saluran 8,7 $\mathrm{km}$ berada di titik gangguan $20 \%$, arus gangguan hubung singkat 1 fasa ke tanah sebesar $279,6678424 \angle-11,48^{\circ}$ A, 2 fasa sebesar $3570,852245 \angle-82,28^{\circ} \mathrm{A}$, dan 3 fasa sebesar $4123,263087 \angle-82,28^{\circ} \mathrm{A}$.

Nilai arus gangguan hubung singkat terbesar dengan panjang total saluran $2,89 \mathrm{~km}$ berada di titik gangguan $20 \%$, arus gangguan hubung singkat 1 fasa ke tanah sebesar $282,8868167 \angle-10,35^{\circ} \mathrm{A}$, 2 fasa sebesar $4176,599504 \angle-87,00^{\circ} \mathrm{A}$, dan 3 fasa sebesar $4822,719447 \angle$ $-87,00^{\circ} \mathrm{A}$.

2. Nilai kedip tegangan terbesar dengan panjang total saluran $8,7 \mathrm{~km}$ yaitu 1 fasa ke tanah sebesar $12711,64253 \angle-2,91^{\circ}$ $\mathrm{V}$ berada di titik gangguan $100 \%, 2$ fasa sebesar $44746,7163<-89,99^{\circ} \mathrm{V}$ berada di titik gangguan $80 \%$, dan 3 fasa sebesar $12695,82462 \angle-69,62^{\circ} \mathrm{V}$ berada di titik gangguan $100 \%$.

Nilai kedip tegangan terbesar dengan panjang total saluran 2,89 yaitu1 fasa ke tanah sebesar $11781,2491 \angle-0,91^{\circ} \mathrm{V}$ berada di titik gangguan $80 \%, 2$ fasa sebesar $45531,06148 \angle-89,97^{\circ} \mathrm{V}$ berada di titik gangguan $100 \%$, dan3 fasa sebesar $7097,078114 \angle-78,79^{\circ} \mathrm{V}$ berada di titik gangguan $100 \%$. 


\section{REFERENSI}

[1] Syahputra, R. (2017). Transmisi dan Distribusi Tenaga Listrik. Yogyakarta: LP3M UMY Yogyakarta.

[2] Wiharya, C., Suyono, H., \& Hasanah, R. N. (2014). Analisis Voltage Sag Pada Sistem Tenaga Listrik PT. Petrochina International Ltd. Sorong. Jurnal EECCIS Vol. 1, No. 1, 55-60.

[3] Cekdin, C., \& Barlian, T. (2013). Transmisi Daya Listrik. Yogyakarta: Andi.

[4] Marsudi, D. (2016). Operasi Sistem Tenaga Listrik Jilid 3. Yogyakarta: Graha Ilmu.

[5] Arka, G., Mudiana, N., \& Abasana, G. (2014). Studi Analisa Gangguan Hubung Singkat 1 Fasa Ke Tanah Pada SUTT $150 \mathrm{kV}$ Untuk Setting Relay OCR (Aplikasi GI PIP - Pauh Limo). Jurnal Teknik Elektro ITP Volume 3 No. 2, 95104.

[6] Dugan, R., McGranaghan, M., Santoso, S., \& Beaty, H. (2002). Electrical Power Systems Quality Second Edition. New York: The McGraw-Hill Companies. 